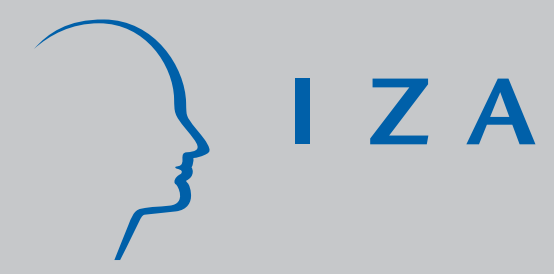

IZA DP No. 3277

Residential Peer Effects in Higher Education: Does the Field of Study Matter?

\author{
Giorgio Brunello \\ Maria De Paola \\ Vincenzo Scoppa \\ J anuary 2008
}




\title{
Residential Peer Effects in Higher Education: Does the Field of Study Matter?
}

\author{
Giorgio Brunello \\ University of Padova, \\ CESifo and IZA
}

Maria De Paola

University of Calabria

Vincenzo Scoppa
University of Calabria

Discussion Paper No. 3277

January 2008

IZA
P.O. Box 7240
53072 Bonn
Germany

Phone: +49-228-3894-0

Fax: +49-228-3894-180

E-mail: iza@iza.org

\begin{abstract}
Any opinions expressed here are those of the author(s) and not those of IZA. Research published in this series may include views on policy, but the institute itself takes no institutional policy positions.

The Institute for the Study of Labor (IZA) in Bonn is a local and virtual international research center and a place of communication between science, politics and business. IZA is an independent nonprofit organization supported by Deutsche Post World Net. The center is associated with the University of Bonn and offers a stimulating research environment through its international network, workshops and conferences, data service, project support, research visits and doctoral program. IZA engages in (i) original and internationally competitive research in all fields of labor economics, (ii) development of policy concepts, and (iii) dissemination of research results and concepts to the interested public.
\end{abstract}

IZA Discussion Papers often represent preliminary work and are circulated to encourage discussion. Citation of such a paper should account for its provisional character. A revised version may be available directly from the author. 


\section{ABSTRACT \\ Residential Peer Effects in Higher Education: Does the Field of Study Matter?*}

Economists have a poor understanding of the mechanisms underlying reduced-form college peer effects. In this paper we explore a candidate mechanism, the provision of school effort. We show that, when earnings reflect individual educational performance as well as the field of study selected at college, and individual effort is a function of expected earnings, the size of the peer effect varies by field. Using data from a middle-sized public university located in Southern Italy and exploiting the random assignment of first year students to college accommodation, we find evidence that peer effects are positive and statistically significant for students enrolled in the fields of Engineering, Maths and Natural Sciences - which are expected to generate higher earnings after college - and not different from zero for students enrolled in the Humanities, Social and Life Sciences, which give access to lower payoffs. An implication of our model is that shocks affecting college wage premia may alter the size of peer effects.

JEL Classification: I21, Z13, J24

Keywords: peer effects, random assignment, Italy, fields of study, optimal effort

Corresponding author:

Giorgio Brunello

Department of Economics

University of Padova

via del Santo 33

35100 Padova

Italy

E-mail: giorgio.brunello@unipd.it

\footnotetext{
* We would like to thank Daniele Checchi, Giovanni Mastrobuoni and Michele Pellizzari for advice, the administration of University of Calabria for providing access to the data, Carlo Maria Verrina and Massimo Colafati of the Residential Office for many useful conversations, and Anna Russo and Monya Perricone for providing assistance with the use of the data. The usual disclaimer applies.
} 


\section{Introduction}

Understanding the nature and importance of peer group effects in education is crucial for education policy. One important question is whether the allocation of students to classes should mix or segregate abilities. The answer varies depending on the existence and nonlinearity of peer effects in the classroom (see Hoxby, 2000). Motivated by the relevance for policy, a small industry has developed which seeks to estimate the existence, size and nonlinearity of peer effects. Unfortunately, estimation is plagued by numerous problems, including the self-selection, reflection and correlated effects described by Manski, 1993.

Following Sacerdote, 2001, and Zimmermann, 2003, a popular approach in this literature has been to investigate roommate peer effects, because in a number of universities and colleges the allocation of students to rooms can be argued to be conditionally random. The implied orthogonality of peer abilities with respect to omitted confounders and the use of a reduced-form equation to overcome the reflection problem allows to identify peer effects, thereby by-passing some of the thorny econometric issues indicated above. Successful identification, however, comes at a price. The empirical evidence in favour of roommate peer effects is limited: many studies find small or no effects, which vary in relation to the sample used (for an assessment of the empirical literature see Foster, 2006; Stinebrickner and Stinebrickner, 2006).

Even if reduced - form peer effects can be proven to exist, one wonders about the economic and social mechanisms generating them. As remarked by Foster, 2006, “..economists have an under-developed understanding of the processes likely to underlie reduced - form peer effects". In this paper, we explore the provision of school effort as a candidate economic mechanism which affects the size of peer effects. If labour market earnings reflect individual educational performance as well as the field of study selected at college, optimal effort chosen by students varies by field in response to expected earnings differences, even when the cost of effort and the technology regulating school performance are homogeneous across fields. While peer ability affects both the marginal costs and the marginal benefits of school effort, the intensity of the effect on the latter - and on school performance - crucially depends on the field specific expected returns to successful college education. 
This economic mechanism has the interesting implication that the size of the peer effect is not invariant to labour market shocks affecting the college wage premium in different fields of study. To illustrate, an expected demand shift which increases the demand for engineers and their relative earnings - compared to other fields of study should increase optimal effort and hence the peer effect among students enrolled in Engineering, even though the technology of production of human capital and the cost of effort while at school is invariant across fields.

We submit the hypothesis that the size of exogenous peer effects vary with the field of study to empirical scrutiny, using data on residential roommates at a middle - sized Italian University. We start by showing that college wages in Italy are significantly affected by individual college performance and field of study. Next, we document that the allocation of students to rooms in the residential halls of the selected university is conditionally random. Finally, we estimate reduced - form linear peer effect models, as in most of the empirical literature, and find evidence that the size of the roommate peer effect varies significantly with the field of study and is higher in the fields in which students expect higher wage premia.

The paper is organized as follows. Section 2 is a brief review of the empirical literature. Section 3 introduces the theoretical model and presents empirical evidence on the relationship between the field of study and college earnings. Section 4 describes the data and the assignment mechanism of students to rooms in the residential halls. Section 5 shows our empirical results. Conclusions follow.

\section{Review of the Empirical Literature}

Most empirical studies which investigate peer group effects at college exploit the presence of a mechanism which randomly assigns students to rooms and peers. This literature has focused mainly on the residential peer group effects involving roommates, relying on a housing assignment process that allocates each student to a roommate exogenously. Results are far from being conclusive: many studies find small or no peer effects and the significance and size of peer effects often changes in relation to the sample used. 
Sacerdote, 2001, finds weak evidence of peer effects when roommate characteristics are entered linearly, but significant and positive effects when non-linearities are introduced. Zimmerman, 2003, finds that students in the middle $70 \%$ of the SAT distribution perform worse when they have a roommate in the bottom $15 \%$. These effects are present for males but not for females. Stinebrickner and Stinebrickner, 2006, differently from the previous two studies - which use data from very selective US colleges - consider a sample of more heterogeneous students from Berea College. They find positive peer effects (limited to females) when peer quality is measured with high school grades, but no effect when alternative measures of peer ability are adopted.

In a similar vein Kremer and Levy, 2003 find no effect of the roommate academic background on student performance, but show that pre-college drinking habits among male students tend to negatively influence their roommates' GPA, especially among lowerperforming students. Foster, 2006, considers students from the University of Maryland and finds no peer effects for women, and only modest peer effects for men. In addition, she shows that friends do not impact on individual school performance more than randomly selected peers. Finally, Winston and Zimmermann, 2003, use data on three schools from the College and Beyond database and find evidence of statistically significant and positive peer effects, at least for one of the schools considered ${ }^{1}$.

\section{Optimal Educational Effort, Peer Effects and the Field of Study}

We start this section by introducing a simple theoretical model of student effort choice in the presence of peer effects, which shows how these effects can vary with the field of study. Next we present some empirical evidence in support of the view that labour market earnings vary significantly with the field of study, as well as with individual college performance.

\subsection{The Model}

${ }^{1}$ A recent contribution to this literature, which uses Italian data, is De Giorgi, Pellizzari and Radaelli, 2006. These authors use random assignment to teaching classes as identification strategy and estimate peer effects on the choice of the field of study. 
Assume that students use the same technology for the production of college performance, and also share the same cost of effort function. They differ however in their personal characteristics, such as ability, in the ability of their peer and in the field of study they engage in. Define individual performance at college of student $i$ as $y_{i}$ and assume that it is a linear function of individual (pre-determined) ability $q_{i}$, effort $e_{i}$, roommate ability $q_{j}$ and the educational resources in the selected field $F$ (which include teacher quality, the availability and quality of labs, etc.):

$$
y_{i}=\lambda e_{i}+\gamma q_{i}+\delta q_{j}+\eta F+\varepsilon_{i}
$$

The linear specification simplifies the algebra without affecting the key results, and is also consistent with the empirical specification adopted in most of the literature. While ability is exogenously given, effort is subject to individual choice. In order to pass examinations, a student needs to perform above or at the standard $s$. Conditional on individual and peer ability, the higher the standard, the higher the effort required to meet the standard (see Costrell, 1994). Passing rather than failing exams depends also on a random event $\varepsilon$ (luck), which we assume to have a standard normal distribution $\varepsilon \approx N(0,1)$.

Using $\Phi$ for the normal distribution function, the individual probability of passing the standard is:

$$
P_{i}=\operatorname{Pr}\left(y_{i} \geq s_{f}\right)==1-\Phi\left(s_{f}-\lambda e_{i}-\gamma q_{i}-\delta q_{j}-\eta F\right)
$$

Higher expected performance at school yields higher expected labour market returns, which differ also across fields, possibly reflecting variations in relative demand and supply. The expected wage $w$ of individual $i$ graduating in field $f$ is:

$$
w_{i f}=\alpha_{f} E\left(y_{i}\right)
$$

where the multiplicative formulation is consistent with the log-linear Mincerian equations 
estimated in the empirical literature ${ }^{2}$. In the event of failure to pass exams and graduate, labour market returns are normalized to zero.

Assuming risk neutrality, individual expected utility is increasing in the expected benefits of higher effort and decreasing in the costs of effort. Higher effort increases both college performance and the probability of passing the exams and graduate. We model the cost of effort as a quadratic function

$$
C\left(e_{i}, q_{i}, q_{j}\right)=\frac{\psi e_{i}^{2}}{2}-x q_{i} e_{i}-z q_{j} e_{i}
$$

where we allow individual and peer ability to reduce the cost of effort.

Expected utility is

$$
U_{i}=P_{i} \alpha_{f} E\left(y_{i}\right)-\frac{\psi e_{i}^{2}}{2}+x q_{i} e_{i}+z q_{j} e_{i}
$$

Rational students choose effort to maximize utility. The first order condition for a maximum is

$$
P_{i} \alpha_{f} \lambda+\alpha_{f}\left(\lambda e_{i}+\gamma q_{i}+\delta q_{j}+\eta F\right) \lambda \phi(.)-\psi e_{i}+x q_{i}+z q_{j}=0
$$

where $\phi($.$) is the density function of the error term \varepsilon$.

In order to study how individual effort varies when peer ability is marginally increased, it is useful to adopt the following first order Taylor approximations of the normal distribution and density functions around their mean

$$
\begin{gathered}
\Phi=\frac{1}{2}+\phi(0)\left(s_{f}-\lambda e_{i}-\gamma q_{i}-\delta q_{j}-\eta F\right) \\
\phi=\phi(0)
\end{gathered}
$$

\footnotetext{
${ }^{2}$ The implicit assumption here is that students know the wage function associating performance to earnings and form their expectations from realizations, a standard assumption in this literature. See the discussion in Brunello, Lucifora and Winter Ebmer, 2004.
} 
Using [7] in [6] we can re-write the first order condition as follows:

$$
\left(\frac{1}{2}-\phi(0)\left(s_{f}-\lambda e_{i}-\gamma q_{i}-\delta q_{j}-\eta F\right)\right) \alpha_{f} \lambda+\alpha_{f}\left(\lambda e_{i}+\gamma q_{i}+\delta q_{j}+\eta F\right) \lambda \phi(0)-\psi e_{i}+x q_{i}+z q_{j}=0
$$

where the second order conditions require that $\Delta_{f}=\psi-2 \alpha_{f} \lambda^{2} \phi(0)>0$. Solving for optimal individual effort we obtain:

$$
e_{i}=\mu+\left[\frac{2 \alpha_{f} \lambda \phi(0)+x}{\Delta_{f}}\right] \gamma q_{i}+\left[\frac{2 \alpha_{f} \lambda \phi(0)+z}{\Delta_{f}}\right] \delta q_{j}+\left[\frac{2 \alpha_{f} \lambda \phi(0)}{\Delta_{f}}\right] \eta F
$$

where $\mu=\left[\frac{\alpha_{f} \lambda}{2}-s_{f} \alpha_{f} \lambda \phi(0)\right] \frac{1}{\Delta_{f}}$.

Peer ability $q_{j}$ positively affects individual effort by reducing its marginal cost and by increasing its marginal benefit. Since the marginal benefit of effort is increasing in the (expected) labour market return $\alpha_{f}$, the size of the peer effect on effort - and consequently on school performance - is larger in the fields that are expected to generate a higher monetary payoff after graduation.

Replacing [8] into [1] yields:

$$
y_{i}=\lambda \mu+\gamma\left[1+\frac{2 \alpha_{f} \lambda^{2} \phi(0)+x}{\Delta_{f}}\right] q_{i}+\delta\left[1+\frac{2 \alpha_{f} \lambda^{2} \phi(0)+z}{\Delta_{f}}\right] q_{j}+\eta\left[1+\frac{2 \alpha_{f} \lambda^{2} \phi(0)}{\Delta_{f}}\right] F+\varepsilon_{i}
$$

The reduced-form equation [9] shows that individual performance at college is affected by own ability, peer ability and educational resources. We conclude that the size of the peer effect $\delta\left[1+\frac{2 \alpha_{f} \lambda^{2} \phi(0)+z}{\Delta_{f}}\right]$ depends both on the parameters of the common technology and cost of effort functions and on the field specific (conditional) wage premium $\alpha_{f}:^{3}$ the

\footnotetext{
${ }^{3}$ Notice that denominator $\Delta_{f}$ is decreasing in $\alpha_{f}$.
} 
higher the premium the stronger the incentive to pass the threshold and graduate, and the higher the effort and the contribution of the peer effect to effort. The model produces two empirical testable implications: first, the size of the peer effect should be larger in fields where the labour market payoff is higher; second, a similar relationship should hold for own ability.

\subsection{College Earnings, Academic Performance and the Field of Study}

In previous sub-section we have postulated that individual earnings after college depend on the field of study and are an increasing function of individual performance. We submit this hypothesis to empirical scrutiny by using the 2001 wave of the Survey of college graduates in Italy (ISTAT, “Indagine statistica sull'inserimento professionale dei laureati”), which contains information on earnings three years after graduation and allows us to control both for the field of study and for individual performance at college.

Following Brunello and Cappellari, 2007, we regress log net monthly wages on individual performance, measured by the final graduation marks, two dummies for the field of study (the scientific group, which includes Maths, Sciences and Engineering, and the group including the Humanities and Social Sciences, while the remaining fields, including Life Sciences, are in the constant term) and the following vector of observables: gender, college attended, region of employment, labour market experience and type of job, parental background in terms of occupation and education, year of birth, the number of siblings, the duration of college studies, the type of high school attended (whether generalist or technical/professional) and the marks reported in the high school graduation exam. We also include interactions between parental education and occupation, on the one hand, and marks and school types, on the other.

In estimating the wage equation we make the assumption that, conditional on the observables, there is no selection into college and faculty according to students unobserved ability, so that the coefficients can be consistently estimated. Clearly, the validity of such assumption depends on how well we control for factors that are related to individual ability and that may influence college choice. While there is no guarantee that our assumption is going to be met, we stress that the vector of observables consists of a detailed list of control factors, including interactions, which leads us to believe that omitted variables bias 
- if existent - is mild.

Table 1 presents the results of the wage equation and shows that log earnings are significantly affected by the final graduation marks: evaluated at the sample means, we find that a 10 percent increase in the final marks yields a 2.77 percent increase in net monthly earnings three years after graduation. We also find that graduating in a scientific field yields a 8.2 percent earnings premium with respect to graduating in the Humanities and Social Sciences, and a 10.4 percent premium with respect to other fields such as Medicine ${ }^{4}$. This evidence suggests that - ceteris paribus - we should expect a larger roommate peer effect among students enrolled in scientific fields such as Engineering and Maths and Sciences.

Table 1. The Impact of Graduation Marks and the Field of Study on Earnings. Dependent Variable: log net monthly earnings

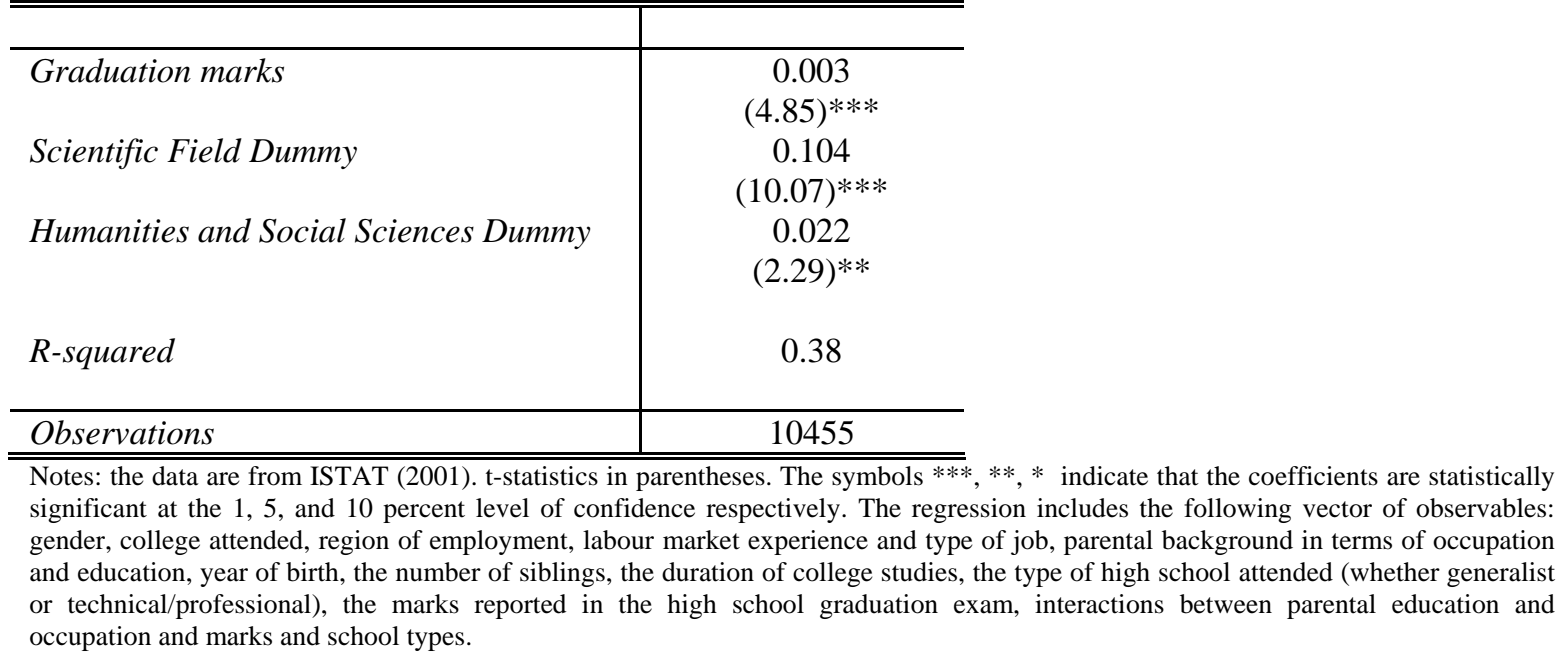

\section{Data and the Assignment of Students to Rooms}

We use administrative data covering students who live on campus at the University of Calabria. The University of Calabria is a middle-sized public university located in the South of Italy, which currently enrols about 33,000 students in six fields of study (Economics, Pharmacy and Nutritional Sciences, Engineering, Humanities, Math and Sciences and Political Science), ${ }^{5}$ and was ranked second in the 2004 list of Italian public

\footnotetext{
${ }^{4}$ Both premia are significantly different from zero at the $1 \%$ level of confidence.

${ }^{5}$ After the 2001 reform, the Italian universities offer both first level degrees, lasting three years, and more advanced degrees, lasting two years.
} 
universities of similar size for the relative quality of its services, infrastructures, computerization and financial support to students ${ }^{6}$. The University of Calabria offers accommodation to nearly 2100 entitled students - close to one fifth of them are freshmen (on average 460 each year). There are 12 residence halls (blocks), divided in flats and rooms. Six of these halls are located on campus and the remaining six are outside campus, at a distance of 3 to 6 kilometres.

Our data on the cohorts of students enrolled from 2000-2001 to 2006-2007 are drawn from the University Residential Office's records and from the administrative files of student exams, and include information both on individual background characteristics and on academic outcomes - in terms of passed exams and grades obtained in each exam. Individual background characteristics include gender, the type of High School attended, the High School Final Grade, the province of residence and parental economic conditions, captured by a synthetic administrative indicator called ISEE, which takes into account household income and wealth, and the number of household components. To be admitted in the halls of residence, a student must meet some requirement in terms of value of ISEE and place of residence ${ }^{7}$. Conditional on admission, we have information on housing assignment - the hall, the flat and the room.

As in most of the empirical literature, we restrict our attention to incoming freshmen, for whom we are confident that residence assignment is conditionally random ${ }^{8}$. The assignment mechanism is as follows: first, students applying for University residence are ranked by the Residential Office according to their economic conditions - measured by ISEE; second, residential places are assigned sequentially, starting with the students at the top of the list, that is, those with a lower value of ISEE. Students can only choose the residence hall. Conditional on the choice of the hall and on the presence of vacancies, flats and rooms are assigned by the Residential Office depending on availability ${ }^{9}$.

Differently from the American colleges studied in the literature (see Sacerdote, 2001, and Zimmermann, 2003, among others), applicants are not required to fill any

\footnotetext{
${ }^{6}$ See the ranking at http://www.repubblica.it/speciale/2004/censis/classifiche/mediatenei.html

${ }^{7}$ Notice that students living in the area near the University - who reside in towns located at approximately less than $40 \mathrm{~km}$ from college - cannot apply for accommodation, independently of their income.

${ }^{8}$ Older students can try to change the roommate to live with, depending on availability.

${ }^{9}$ More in detail, the eligible student is asked by the personnel of the Residential Office to choose one among the available halls of residence in the University Campus. If a vacancy is available in the selected hall, the student is assigned. If there is no vacancy, the student is prompted to select another hall, and the iteration continues until convergence. Clearly, students coming first have greater choice.
} 
housing questionnaire. Therefore, places in rooms and flats are assigned to students of the same gender independently of personal preferences for smoking, music and else. Furthermore, a freshman can be assigned both to other freshmen and to senior students.

Since students are assigned sequentially to rooms according to their economic conditions, a potential outcome of the assignment process might be that students end up in pairs or groups characterized by similar economic conditions and by similar academic ability, which could happen if the latter is strongly correlated with the former. This risk appears to be negligible in our data for two reasons: first, about $57 \%$ of freshmen end up with senior roommates, who could have changed rooms after their initial allocation as freshmen; second, even if students have very similar "formal” economic conditions, their real economic conditions may be quite different, due to the endemic understatement of income and wealth in the South of Italy. While the indicator of economic conditions used by the Residential Office ranged between 0 to about 13.000 euros in 2006, these very low values might have resulted from the fact that a substantial part of household income is earned in the underground economy and not reported ${ }^{10}$.

We identify the peer with the roommate. Whether this is the peer of "potential influence" is obviously an open question, as discussed in detail by Stinebrickner and Stinebrickner, 2006. It is certainly the definition used by the bulk of previous empirical research. Since the emphasis of this paper is on the interaction between peer effects and field of study, we prefer to adopt a definition of peers already implemented in the literature ${ }^{11}$.

Our initial sample consists of 2687 freshmen with a residential place at the University Campus from year 2000 to 2006. After dropping 675 observations corresponding to individuals assigned to single rooms and 589 additional observations because of missing values in one or more relevant variables, we end up with a final sample of 1423 first year students - 1193 assigned to a double room, 217 to a triple room and 13 to quads. Our measure of student performance at college, or GPA, is the average grade earned in the exams passed during the first year at college. Since courses vary in their difficulty, we weight each grade with the number of credits assigned to the course. The variable GPA ranges between 18 - the minimum passing line - and 30.

\footnotetext{
${ }^{10}$ According to the National Statistical Institute, irregular labour in Calabria covers 31 percent of total labour, compared to a national average of 13.4. See ISTAT, 2004.

${ }^{11}$ We also experiment with an alternative definition of peer, the flatmate, but with no significant results.
} 
In this literature, pre-determined academic ability is based on the results of standardized test scores, such as the SAT for the US. No such test is available in Italy before college entry. Furthermore, compared to the US, where secondary school is comprehensive, Italian students are tracked fairly early - at age 14 - into general and vocational tracks. Even though the final exit exam is national, the contents of the exam vary according to the type of secondary school. Tracking introduces important heterogeneity in the final grade attained at the time of high school graduation.

In order to mitigate this problem, we use the outcomes of international cognitive tests - taken at age 15 and recently carried out by the OECD under the PISA project - as measures of the quality of secondary schools. We extract our measure of individual academic ability - which we call ACA for brevity - from a principal component analysis which includes two factors, the marks at graduation from secondary school and the standardized average test score for each type of high school - which covers maths, reading, science and problem solving - from PISA 2003 (see OECD, 2004). Since most of the students enrolling at the University of Calabria are from the South of Italy, we use the standardized PISA test scores for this part of the country ${ }^{12}$.

Peer ability is the roommate's ability in the case of a double room, and the simple average of roommates' ability in the case of triple and larger rooms ${ }^{13}$. Table 2 shows the descriptive statistics for our sample of students. Own and peer academic ability ranges between 69.23 to 100 . Average ACA is at 88.65, higher in the more demanding general track (Lyceum) than in the vocational track; average GPA is slightly above 24, highest in the Humanities and lowest in Engineering. The distribution of students across fields is not even, with 26\% enrolled in the Faculty of Economics, 8\% in the Faculty of Pharmacy and Nutritional Sciences, 19\% in Engineering, 27\% in the Humanities, 9\% in Mathematics and Natural Sciences and 8\% in the Faculty of Political Science.

To confirm the randomness of the assignment mechanism of students to residential halls, we follow the empirical literature and regress individual ability ACA on the peer's $A C A$ and additional controls, which include a gender dummy, cohort and halls of residence effects. If entering students are sorted into rooms by ability, then the coefficient attracted by the peer's ACA should be positive and statistically significant.

\footnotetext{
${ }^{12}$ Bratti, Checchi and Filippin, 2007, present evidence on the territorial differences in PISA test scores across the North and the South of Italy.

${ }^{13}$ Peers can be freshmen, sophomores or senior students.
} 
Table 2. Descriptive statistics

\begin{tabular}{lccccc}
\hline \hline Variables & Mean & Std Dev & Min. & Max. & Obs. \\
\hline Female & & & & & \\
ACA average & 0.681 & & 0 & 1 & 1423 \\
ACA Lyceum & 88.652 & 6.78 & 69.23 & 100 & 1423 \\
ACA Technical/vocational & 94.125 & 4.65 & 69.23 & 94.25 & 943 \\
& 85.172 & 5.51 & 79.14 & 100 & 480 \\
GPA average & & & & & \\
GPA Economics & 24.078 & 2.78 & 18 & 30 & 1423 \\
GPA Pharmacy and Nutritional Sciences & 23.381 & 2.41 & 18 & 30 & 379 \\
GPA Engineering & 22.756 & 2.45 & 18 & 30 & 117 \\
GPA Humanities & 22.508 & 2.63 & 18 & 30 & 272 \\
GPA Mathematics and Natural Sciences & 26.070 & 2.12 & 18 & 30 & 392 \\
GPA Political Science & 23.764 & 2.50 & 18 & 30 & 124 \\
& 24.824 & 2.73 & 18 & 30 & 139 \\
\hline \hline
\end{tabular}

Table 3 presents the results of this regression for the full sample and for two subsamples, one including the faculties of Engineering and Mathematics and the other including the remaining four faculties in the University. It turns out that in no case we fail to reject the hypothesis that the conditional correlation between individual and peer ability is not statistically significant. Therefore we conclude that the allocation of freshmen to rooms is conditionally random.

Table 3. Endogeneity checks. Dependent Variable: Individual Academic Ability (ACA)

\begin{tabular}{l|ccc}
\hline \hline & $(1)$ & $(2)$ & $(3)$ \\
\hline \multirow{2}{*}{ ACA Roommate } & 0.026 & 0.064 & -0.007 \\
& $(0.88)$ & $(1.15)$ & $(0.23)$ \\
& & & \\
Gender Dummy & YES & YES & YES \\
Cohort Dummies & YES & YES & YES \\
Halls Dummies & YES & YES & YES \\
& & & \\
R-squared & 0.03 & 0.15 & 0.05 \\
Observations & 1423 & 396 & 1027 \\
\hline
\end{tabular}

Notes: t-statistics in parentheses. The symbols $* * *, * * *$ indicate that the coefficients are statistically significant at the 1,5 , and 10 percent level of confidence respectively.

\section{The Empirical Findings}

Our empirical specification is based on Eq. (9), and is similar to the traditional empirical approach implemented for instance by Zimmerman (2003) and Sacerdote (2001). 
We estimate

$$
G P A_{i}=c_{f}+\beta_{1 f} A C A_{i}+\beta_{2 f} A C A_{j}+\beta_{3 f} X_{i}+v_{i}
$$

where $X$ is a vector of controls, which include cohort, gender and residence dummies. By including these dummies we intend to control for the correlated un-observables problem, which arises if there is some group - specific component in the error term (see Soetevent, 2006). Notice that we explicitly allow the estimated coefficients to vary with the field of study, in line with the theoretical model. If roommates are allocated randomly, the OLS estimate of peer effects is consistent even in the presence of omitted variables which affect GPA (Sacerdote, 2001).

Table 4 presents the results for the six faculties of the University. There is evidence that individual academic performance has a positive and statistically significant effect on individual GPA at college. In the Humanities, Social and Life sciences the estimated coefficient associated to the peer's academic ability is either negative or close to zero, but never statistically significant. On the other hand, the same coefficient is positive but still rather imprecisely estimated in Engineering, Mathematics and Natural Sciences.

Table 4. Estimates of Peer Effects (Reduced form) by Field of Study. Dependent Variable: Individual GPA

\begin{tabular}{|c|c|c|c|c|c|c|}
\hline & Economics & $\begin{array}{c}\text { Pharmacy, } \\
\text { Nutritional } \\
\text { Sciences }\end{array}$ & Humanities & $\begin{array}{l}\text { Political } \\
\text { Science }\end{array}$ & Engineering & $\begin{array}{c}\text { Mathematics } \\
\text { and Natural } \\
\text { Sciences }\end{array}$ \\
\hline$A C A$ & $\begin{array}{c}0.170 \\
(9.58)^{* * *}\end{array}$ & $\begin{array}{c}0.104 \\
(3.91)^{* * *}\end{array}$ & $\begin{array}{c}0.138 \\
(7.62)^{* * *}\end{array}$ & $\begin{array}{c}0.216 \\
(7.01)^{* * *}\end{array}$ & $\begin{array}{c}0.194 \\
(9.13)^{* * *}\end{array}$ & $\begin{array}{c}0.230 \\
(10.13)^{* * *}\end{array}$ \\
\hline ACA Roommate & $\begin{array}{r}-0.011 \\
(0.62)\end{array}$ & $\begin{array}{c}-0.006 \\
(0.15)\end{array}$ & $\begin{array}{l}-0.024 \\
(1.50)\end{array}$ & $\begin{array}{l}0.005 \\
(0.14)\end{array}$ & $\begin{array}{l}0.032 \\
(1.59)\end{array}$ & $\begin{array}{c}0.051 \\
(1.73)^{*}\end{array}$ \\
\hline Female & $\begin{array}{l}0.127 \\
(0.49)\end{array}$ & $\begin{array}{l}-0.033 \\
(0.05)\end{array}$ & $\begin{array}{c}-0.978 \\
(3.60)^{* * *}\end{array}$ & $\begin{array}{l}0.288 \\
(0.48)\end{array}$ & $\begin{array}{c}-0.573 \\
(1.84)^{*}\end{array}$ & $\begin{array}{l}-0.373 \\
(0.83)\end{array}$ \\
\hline Halls Dummies & YES & YES & YES & YES & YES & YES \\
\hline Cohort Dummies & YES & YES & YES & YES & YES & YES \\
\hline Observations & 379 & 117 & 392 & 139 & 272 & 124 \\
\hline$R$ Squared & 0.24 & 0.26 & 0.21 & 0.36 & 0.34 & 0.53 \\
\hline
\end{tabular}

Note: see Table 3

Table 5 presents our findings when we pool all faculties together and include in the regression faculty specific fixed effects. Since the pattern of results in Table 4 suggests that the former four faculties and the latter two faculties are relatively homogeneous as far as 
peer effects are concerned, we also present the results of a specification that pools all fields of study together but allows the coefficients associated to both academic ability and the residential, gender and cohort dummies to vary between the two groups. This is done by interacting these variables with the dummy SCI, which is equal to 1 for the fields of Engineering, Maths and Natural Sciences and to 0 otherwise.

The key finding of the table - in line with our theoretical model and with equation [9] - is that both own academic ability and peer academic effects are significantly larger in the sub-group of scientific faculties $(S C I=1)$ than in the sub-group of Humanities, Social and Life Sciences $(S C I=0)$. In the sub-group of Engineering, Maths and Natural Sciences, the effects of own and peer academic ability are equal to 0.204 (t-statistic: 13.04) and to 0.038 (t-statistic:2.37) respectively.

Table 5. Estimates of Peer Effects (Reduced form): full sample with and without interactions. Dependent Variable: Individual GPA.

\begin{tabular}{|c|c|c|}
\hline & $(1)$ & $(2)$ \\
\hline$A C A$ & $\begin{array}{c}0.170 \\
(19.06)^{* * *}\end{array}$ & $\begin{array}{c}0.151 \\
(13.90)^{* * *}\end{array}$ \\
\hline ACA Roommate & $\begin{array}{c}0.0002 \\
(0.02)\end{array}$ & $\begin{array}{r}-0.017 \\
(1.57)\end{array}$ \\
\hline$A C A * S C I$ & & $\begin{array}{c}0.053 \\
(2.79)^{* * *}\end{array}$ \\
\hline ACA Roommate * SCI & & $\begin{array}{c}0.055 \\
(2.84)^{* * *}\end{array}$ \\
\hline Female & $\begin{array}{c}-0.310 \\
(2.17)^{* *}\end{array}$ & $\begin{array}{l}-0.258 \\
(1.47)\end{array}$ \\
\hline Halls Dummies & YES & YES \\
\hline Cohort Dummies & YES & YES \\
\hline Faculty Dummies & YES & YES \\
\hline Female * SCI & NO & $\begin{array}{l}-0.256 \\
(0.85)\end{array}$ \\
\hline Halls Dummies * SCI & NO & YES \\
\hline Cohort Dummies * SCI & NO & YES \\
\hline $\begin{array}{l}R \text {-squared } \\
\text { Observations }\end{array}$ & $\begin{array}{l}0.41 \\
1423\end{array}$ & $\begin{array}{l}0.43 \\
1423\end{array}$ \\
\hline
\end{tabular}

Note: see Table 3.

How large is the roommate peer effect in the scientific faculties compared to the effects found in the empirical literature? If we take the ratio of the coefficient of the roommate's ACA to the coefficient of the own $A C A$, we find that it is equal to 0.212 in the 
scientific faculties, which compares to 0.042 in Zimmermann (2003), to the range 0.098 to 0.172 in Winston and Zimmerman and to the range 0.073 to 0.193 in Stinebrickner and Stinebrickner (2006). We conclude that, when measured as a percentage of the own background ability effect, the roommate peer effect detected in our study for the sub-group of scientific faculties is not small.

Our theoretical model in Section 3 suggests that differences in the expected returns to college are sufficient to generate variations in the size of own and peer contextual effects, even when the human capital technology and the cost of effort function is the same across students enrolled in different fields. Our evidence on the returns to college shows that graduates in the scientific fields earn - ceteris paribus - higher labour market returns. The evidence in Table 5 corroborates the implications of our model by showing that the size of the own and peer academic effect is larger in the faculties that offer higher expected wage premia.

Our findings have interesting implications on the complex economic mechanism underlying peer effects. Suppose that the economy is hit by asymmetric shocks, that shift the composition of the demand for graduate labour away from economists and towards engineers. These shocks not only are likely to alter expected returns by increasing the wage premium paid to engineers, but they can also affect the size of peer effects at college, because they modify the relative incentives that rational students have to invest in educational effort.

\section{Conclusions}

The existing literature on peer effects in higher education has produced mixed evidence at best. Particularly detrimental to an adequate understanding of the phenomenon - which has many relevant policy implications - is that the economic and social mechanisms producing peer effects are far from clear.

Using administrative data from University of Calabria, a middle-sized public University in Southern Italy, we have investigated whether roommate peer effects vary significantly with the field of study. We have exploited the random assignment of first year students to college accommodation and found evidence that peer effects are positive and 
statistically significant for students enrolled in Engineering, Maths and Natural Sciences, and not different from zero for students enrolled in the Humanities, Social and Life Sciences. The size of the peer effect for scientific faculties is rather large, compared to other studies in the literature.

We have presented a simple theoretical model which suggests that the uncovered differences between fields in the size of the peer effect are generated by the between - fields variation of labour market returns, which affect optimal student effort. Peer ability positively affects individual effort by reducing its marginal cost and by increasing its marginal benefit. Since the marginal benefit of effort is increasing in the expected labour market returns, the size of the peer effect on effort - and consequently on school performance - is larger in the fields that are expected to generate a higher monetary payoff after graduation.

The economic mechanism at play has the interesting implication that the size of the peer effect is not invariant to shocks affecting the college wage premium in different fields of study. Therefore, a demand shift which increases the demand for engineers and their relative earnings - compared to other fields of study - is expected to increase the peer effect in the field of Engineering, even though the technology of production of human capital and the cost of effort while at school is invariant across fields. 


\section{References}

Brunello, G and Cappellari L, 2007, The Labour Market effects of Alam Mater: Evidence from Italy, forthcoming in The Economics of Education Review.

Brunello, G, Lucifora, C and Winter Ebmer, R, (2004), The wage expectations of European college students, Journal of Human Resources, 4, 39, 1116-42.

Bratti M, Checchi D and Filippin A, (2007), Territorial differences in Italian Students' Mathematical Competencies: Evidence from PISA 2003, IZA DP 2603.

Costrell, R (1994), A simple model of educational standards, American Economic Review, 84, 956-71.

De Giorgi, G., Pellizzari, M., Redaelli, S., (2006), "Be as careful of the books you read as of the company you keep. Evidence on peer effects in educational choices”, mimeo.

Foster, G., (2006), "It's not Your Peers, And It's Not Your Friends: Some Progress Toward Understanding the Educational Peer Effect Mechanism”, Journal of Public Economics, pp. 1455-75.

Hoxby, C., (2000), "Peer effects in the classroom: Learning from gender and race variation”, NBER Working Paper 7867.

ISTAT, (2001), Indagine statistica sull'inserimento professionale dei laureati, Rome.

ISTAT, (2004), La misura dell'economia sommersa secondo le statistiche ufficiali, Rome.

Manski, C., (1993), "Identification of Endogenous Social Effects: The Reflection Problem” Review of Economic Studies, 60, pp. 531-542.

Sacerdote, B., (2001), "Peer Effects with Random Assignment: Results for Dartmouth Roommates”, Quarterly Journal of Economics, 681-704.

Stinebrickner, R., Stinebrickner, T., (2006), "What can be learned about peer effects using college roommates? Evidence from new survey data and students from disadvantaged backgrounds”, Journal of Public Economics, pp. 1435-54.

Soetevent, A, (2006), Empirics of the identification of social interactions: an evaluation of the approaches and their results, Journal of Economic Surveys, 20,2, 193-228.

Winston, G and Zimmermann, D, (2003), Peer effects in higher education, NBER Working Paper 9501.

Zimmerman, D., (2003) "Peer Effects in Academic Outcomes: Evidence from a Natural Experiment,” Review of Economics and Statistics, 85(1), pp. 9-23. 